\title{
Alginate microspheres prepared by internal gelation: Development and effect on insulin stability
}

\author{
Catarina M. Silva ${ }^{\mathrm{a}, *}$, António J. Ribeiro ${ }^{\mathrm{b}}$, Isabel Vitória Figueiredo ${ }^{\mathrm{c}}$, \\ Alexandra Rocha Gonçalves ${ }^{\mathrm{d}}$, Francisco Veiga ${ }^{\mathrm{a}}$ \\ ${ }^{a}$ Laboratório de Tecnologia Farmacêutica, Faculdade de Farmácia, Universidade de Coimbra, Rua do Norte, $3000-295$ Coimbra, Portugal \\ ${ }^{\mathrm{b}}$ Laboratório de Tecnologia Farmacêutica, Instituto Superior de Ciências da Saúde-Norte, \\ Rua Central de Gandra, 1317, 4585-116 Gandra, Paredes, Portugal \\ ${ }^{\text {c } L a b o r a t o ́ r i o ~ d e ~ F a r m a c o l o g i a, ~ F a c u l d a d e ~ d e ~ F a r m a ́ c i a, ~ U n i v e r s i d a d e ~ d e ~ C o i m b r a, ~ R u a ~ d o ~ N o r t e, ~} 3000-295$ Coimbra, Portugal \\ ${ }^{\mathrm{d}}$ Departamento de Química, Faculdade de Ciências e Tecnologia, Universidade de Coimbra, 3004-535 Coimbra, Portugal \\ Received 8 July 2005; received in revised form 11 October 2005; accepted 15 October 2005 \\ Available online 26 January 2006
}

\begin{abstract}
Recombinant human insulin was encapsulated within alginate microspheres by the emulsification/internal gelation technique with the objective of preserving protein stability during encapsulation procedure. The influence of process and formulation parameters was evaluated on the morphology and encapsulation efficiency of insulin. The in vitro release of insulin from microspheres was studied under simulated gastrointestinal conditions and the in vivo activity of protein after processing was assessed by subcutaneous administration of extracted insulin from microspheres to streptozotocin-induced diabetic rats. Microspheres mean diameter, ranging from 21 to $287 \mu \mathrm{m}$, decreased with the internal phase ratio, emulsifier concentration, mixer rotational speed and increased with alginate concentration. Insulin encapsulation efficiency, near $75 \%$, was not affected by emulsifier concentration, mixer rotational speed and zinc/insulin hexamer molar ratio but decreased either by increasing internal phase ratio and calcium/alginate mass ratio or by decreasing acid/calcium molar ratio and alginate concentration. A high insulin release, above $75 \%$, was obtained at $\mathrm{pH} 1.2$ and under simulated intestinal $\mathrm{pH}$ a complete dissolution of microspheres occurred. Extracted insulin from microspheres decreased hyperglycemia of diabetic rats proving to be bioactive and showing that encapsulation in alginate microspheres using the emulsification/internal gelation is an appropriate method for protein encapsulation.
\end{abstract}

(C) 2006 Elsevier B.V. All rights reserved.

Keywords: Alginate; Bioactivity; Insulin; Internal gelation; Microspheres

\section{Introduction}

Despite the major advances that have occurred, since insulin introduction in 1922, relating to production, purification and pharmaceutical formulation, insulin-replacement therapy is far from ideal. The optimal method of insulin delivery must be safe, should provide insulin to diabetic patients in a way that will correct the metabolic abnormalities of diabetes mellitus, and must be psychologically and socially acceptable (Brange and Langkjaer, 1997). Although oral administration of insulin is of greatest interest, its low bioavailability has not permitted to achieve an efficient formulation. The entrapment within

\footnotetext{
* Corresponding author. Tel.: +351 239 855085; fax: +351 239855099 .

E-mail address: catarinasilva@ ci.uc.pt (C.M. Silva).
}

microparticulate drug delivery systems, using various kinds of polymers and techniques has been extensively investigated (Damge et al., 1988; Morishita et al., 1992; Mathiowitz et al., 1997; Lowman et al., 1999; Agarwal et al., 2001) to increase the poor permeability across intestinal epithelia and avoid destruction by proteolytic intestinal enzymes. However, in the development of new protein delivery methods, there are several key points that have to be considered, namely, the impact of manufacturing on the integrity of the protein (Cleland et al., 2001). During the formation of microspheres, the protein molecules are often exposed to heat, mechanic stirring, adsorption onto matrix polymer, exposure to organic solvents and surface tension, which may result in a different molecular deterioration of the protein, such as molecular breakdown, denaturation and aggregation ( $\mathrm{Li}$ et al., 2000). Thus, a mild encapsulation method avoiding stress conditions should be selected to 
minimize protein denaturation and the loss of its biological activity.

Alginate is a non-toxic, biodegradable, natural occurring polysaccharide obtained from marine brown algae. It is a linear copolymer composed of 1,4-linked- $\beta$-D-mannuronic acid and $\alpha$-L-guluronic acid residues that gels in the presence of divalent cations, such as calcium, due to the stacking of guluronic acid $(\mathrm{G})$ blocks with the formation of "egg-box" calcium linked junctions (Martinsen et al., 1989). Alginate microspheres have been used for the encapsulation of a wide variety of biologically active agents, including proteins (Coppi et al., 2002), enzymes (Boadi and Neufeld, 2001), antibodies (Albarghouthi et al., 2000), cells (Klinkenberg et al., 2001) and DNA (Quong and Neufeld, 1998), due to the relatively mild crosslinking conditions of preparation. In particular, calcium-alginate microspheres were used to encapsulate insulin by using an extrusion process (Gray and Dowsett, 1988) and an encapsulation efficiency of $65 \%$ was obtained. Insulin was also encapsulated in chitosan-coated alginate microspheres (Hari et al., 1996) but the encapsulation efficiency was very low $(11 \%)$. Strategies to increase the encapsulation efficiency included the complexation of insulin with $\beta$-cyclodextrin (Moses et al., 2000) or the incorporation of insulin in liposomes (Ramdas et al., 2000) before the encapsulation in alginate microspheres.

Microspheres having less than $100 \mu \mathrm{m}$ can be produced by the emulsification/internal gelation technique (Poncelet et al., 1992) by dispersing an alginate solution containing an insoluble calcium salt into an oil. Gelation is achieved by gentle acidification with an oil-soluble acid that causes calcium ion release. Small-sized alginate microspheres may be an adequate system for oral insulin administration since they permit a predictable gastrointestinal transit time and an increased surface area for interaction with the intestinal epithelium. Alginate bioadhesive properties (Chickering et al., 1997) will be favoured by a more intimate contact between intestinal mucosa and lower-sized microspheres. Insulin was encapsulated in alginate microspheres prepared by an emulsion-based process (Jerry et al., 2001) but insulin content was very low $(21 \mathrm{IU} / \mathrm{g})$.

During manufacturing, a large number of parameters may influence the characteristics of the microspheres. We previously investigated the effect of some process and formulation parameters on the morphology and protein encapsulation efficiency of calcium-alginate microspheres prepared by emulsification/internal gelation containing hemoglobin, used as a model protein (Silva et al., 2005).

Based on these considerations, the present work investigates the means for the efficient encapsulation of insulin, which poses more difficulties in respect to protein retention inside microspheres, especially due to its lower molecular weight $(5.8 \mathrm{kDa})$, comparatively to hemoglobin $(64 \mathrm{kDa})$. Process and formulation variables were optimized in order to obtain microspheres presenting the lowest size and the highest encapsulation efficiency of insulin.

The encapsulation efficiency of insulin in alginate microspheres was found to increase when the $\mathrm{pH}$ of the processing medium decreased from 6.0 to 4.0 (Moses et al., 2000). In other studies, insulin encapsulation efficiency in alginate micro- spheres was approximately $97 \%$ (Onal and Zihnioglu, 2002) and 93\% (Wang and He, 2002) and these high values may be justified by the fact that in both studies the $\mathrm{pH}$ of the processing medium was below the isoelectric point of insulin $(\mathrm{p} I=5.3)$, favouring the electrostatic interaction between the protein and alginate.

In this work, the studied process variables were related to the emulsification process and included emulsifier concentration, internal phase ratio and impeller rotational speed. Factors influencing alginate gelling properties, such as calcium/alginate mass ratio, acid/calcium molar ratio and alginate concentration, were also evaluated. Insulin was dissolved in an acetate zinc solution to study the molar ratio between zinc ion and insulin, which may influence insulin degree of association and solubility. When zinc or other divalent metal ions are present, the hexameric form of insulin prevails in neutral and moderately alkaline solutions even at low protein concentrations (Brange et al., 1987).

Furthermore, the in vitro release profile of insulin in simulated gastrointestinal conditions was studied and insulin stability was assessed by bioactivity studies to ensure that insulin-loaded microspheres were able to preserve protein stability during particle processing and recovery.

\section{Materials and methods}

\subsection{Materials}

Sodium alginate $\left(\right.$ Algogel $\left.{ }^{\circledR} \quad 3541\right)$ was obtained from Degussa Texturant Systems (Boulogne-Billancourt, France). This alginate presented a viscosity measured with a rotational viscometer (Visco Star plus, Fungilab, S.A., Barcelona, Spain) for a $1 \%$ solution at $20^{\circ} \mathrm{C}$ of $318 \mathrm{mPa}$. Span ${ }^{\circledR} 80$ was purchased from Fluka Biochemika (Steinheim, Germany). Ultrafine calcium carbonate (Setacarb) was supplied by Omya (Orgon, France) and paraffin oil was supplied by Vaz Pereira (Lisbon, Portugal). Insulin was obtained as a regular human insulin of recombinant DNA origin (Actrapid ${ }^{\circledR} 100 \mathrm{IU} / \mathrm{ml}$ ) from Novo Nordisk A/S (Bagsvaerd, Denmark). Streptozotocin was purchased from Sigma (Steinheim, Germany). All other chemicals used were of analytical reagent grade.

\subsection{Methods}

\subsubsection{Preparation of microspheres}

Microspheres were prepared by emulsification/internal gelation (Poncelet et al., 1992). A basal encapsulation protocol was used to prepare microspheres, which consisted in the following. A $2 \%(\mathrm{w} / \mathrm{v})$ sodium alginate solution was prepared by dissolution of the polymer in insulin solution at $0.1 \%(\mathrm{w} / \mathrm{v})$ obtained by dilution of Actrapid ${ }^{\circledR}$ formulation in water $(1: 2$, v/v). A suspension of $\mathrm{CaCO}_{3}$ at $5 \%$ (w/v) was added to the alginate solution $(7.3 \% \mathrm{Ca}$ /alginate mass ratio, w/w) and, after homogenization, the mixture was dispersed into paraffin oil (30\% internal phase ratio, v/v) containing $1 \%$ (v/v) Span ${ }^{\circledR} 80$ by stirring at $400 \mathrm{rpm}$ through the use of an Ika-Eurostar ${ }^{\circledR}$ mixer (Ika, Staufen, Germany) equipped with a marine impeller. After $15 \mathrm{~min}$ emulsification, $20 \mathrm{ml}$ of paraffin oil containing glacial acetic acid (acid/Ca molar ratio of 3.5) were added to the w/o 
emulsion and stirring continued to permit calcium carbonate solubilization. Microspheres were recovered from oily phase by using an acetate buffer at $\mathrm{pH} 4.5$ (USP XXVII) and successively washed with this buffer until no more oil was detected by optical microscope observation. Microspheres were then frozen in an ethanol bath (Benchtop shell freezer, Freezone ${ }^{\circledR}$ model 79490 , Labconco, USA) at $-40^{\circ} \mathrm{C}$ and freeze-dried (Lyph-lock 6 apparatus, Labconco, USA) at $0{ }^{\circ} \mathrm{C}$ for, at least, $48 \mathrm{~h}$.

Process and formulation variables were investigated for optimization of microspheres properties by individually changing the preparation conditions in the described basal protocol with all other parameters being held constant. The variables tested included emulsifier concentration $(0,0.5$, and $1 \%)$, internal phase ratio $(30,40$, and $50 \%)$, mixer rotational speed $(200,400$, and $600 \mathrm{rpm}), \mathrm{Ca} /$ alginate mass ratio $\mathrm{w} / \mathrm{w}(5.0,6.0,7.3,8.7,10.0$, and $16.7 \%)$, acid/Ca molar ratio (1.5/1, 2/1, and 3.5/1), alginate concentration $(2.0,2.5$, and $3.0 \%)$ and insulin dilution media (zinc acetate at $0,0.2,0.4$ and $0.6 \mathrm{mM}$ ) that permitted to obtain different $\mathrm{Zn} /$ insulin hexamer molar ratios (2.0, 5.5, 9.0 and 13.0, respectively). The mean yield for the recovery of microspheres was $70.3 \pm 8.6 \%$.

\subsubsection{Morphological and particle size analysis}

Morphology of hydrated microspheres was monitored by optical microscopic observation using an optical microscope Olympus BH2-UMA equipped with a Cue-2 image analyser (Olympus, Tokyo, Japan). The shape and surface texture of microspheres was examined by scanning electron microscopy (SEM) (JEOL JSM- $840^{\circledR}, 10 \mathrm{kV}$, Tokyo, Japan). The samples were mounted on metal stubs, using double sided adhesive tape, gold coated under vacuum and then examined. Size distribution of microspheres was determined in washing media by laser diffractometry (Fraunhofer model) using a Coulter LS130 particle analyser, with a size range from 0.1 to $1000 \mu \mathrm{m}$. Measurements were made in triplicate for each batch. Particle size is expressed as volume mean diameter $(\mu \mathrm{m}) \pm$ standard deviation (S.D.) values related to the mean. Polydispersity was determined by the SPAN factor (El-Mahdy et al., 1998) expressed as SPAN $=[D(\mathrm{v}, 90)-D(\mathrm{v}, 10)] / D(\mathrm{v}, 50)$, where $D(\mathrm{v}, 90), D(\mathrm{v}, 10)$ and $D(\mathrm{v}, 50)$ are volume size diameters at 90,10 and $50 \%$ of the cumulative volume, respectively. A high value of SPAN indicates a wide distribution in size and a high polydispersity.

\subsubsection{Encapsulation efficiency}

To determine the encapsulation efficiency of insulin, $10 \mathrm{mg}$ of lyophilized insulin-loaded microspheres were accurately weighed and incubated in $10 \mathrm{ml}$ of hydrochloric acid buffer at pH 1.2 (USP XXVII), under magnetic stirring $(100 \mathrm{rpm} / 2 \mathrm{~h}$ ). Microspheres were then transferred by centrifugation into $10 \mathrm{ml}$ phosphate buffer at pH 6.8 (USP XXVII) and magnetically stirred during $1 \mathrm{~h}$, to obtain complete dissolution. Samples were withdrawn after acid and phosphate incubation and analysed by high performance liquid chromatography (HPLC) as described below. The encapsulation efficiency of insulin was calculated from the difference between the theoretical initial amount of pro- tein and the total insulin recovered from microspheres. Assays were performed in triplicate.

\subsubsection{In vitro release studies}

A multiple stirring points plate was used for in vitro release studies using simulated gastrointestinal conditions without enzymes and a stirring rate of $100 \mathrm{rpm}$. Insulin-loaded microspheres $(20 \mathrm{mg}$ ) were placed in $20 \mathrm{ml}$ of hydrochloric acid buffer at pH 1.2 (USP XXVII). After $2 \mathrm{~h}$, the microspheres were transferred by centrifugation to $20 \mathrm{ml}$ of phosphate buffer at $\mathrm{pH} 6.8$ (USP XXVII) and incubated for $2 \mathrm{~h}$. Two milliliter of sample was taken at appropriate intervals from both media and analysed by HPLC as described below. Assays were performed in triplicate.

\subsubsection{Insulin analysis}

Samples withdrawn from acidic medium were centrifuged $(13,400 \mathrm{rpm} / 10 \mathrm{~min})$ and the supernatant was used for insulin analysis. Samples obtained from phosphate buffer were mixed with $\mathrm{NaOH} 0.2 \mathrm{M}$ to raise $\mathrm{pH}$ above 7.0 followed by addition of ethanol $(50 / 50, \mathrm{v} / \mathrm{v})$ to precipitate alginate. After mixing, samples were centrifuged $(13,400 \mathrm{rpm} / 10 \mathrm{~min})$ and the recovered supernatant was assayed for insulin.

The concentration of insulin was determined by using an HPLC system (model HP1100 series, Hewlett Packard, Germany) equipped with an autosampler (Agilent 1100 series, Germany). A reversed-phase X-Terra C-18 column, $5 \mu \mathrm{m}$, $4.6 \mathrm{~mm} \times 250 \mathrm{~mm}$ (Waters, USA), with a Purospher ${ }^{\circledR}$ STAR RP-18 precolumn, $5 \mu \mathrm{m}, 4 \mathrm{~mm} \times 4 \mathrm{~mm}$ (Merck, Germany) was employed. Mobile phase A consisted of $0.04 \%$ trifluoroacetic acid (TFA) in water and mobile phase B was $0.04 \%$ TFA in acetonitrile. A linear gradient of 30-40\% B over 5 min was used with a flow rate of $1.2 \mathrm{ml} / \mathrm{min}$. Injections of $20 \mu \mathrm{l}$ were made with the autosampler. The UV detector was set at $210 \mathrm{~nm}$ and HPLC analysis was carried at $27^{\circ} \mathrm{C}$. A retention time of $4.5 \mathrm{~min}$ was obtained.

\subsubsection{Diabetic animal model}

Wistar male rats, weighting between 250 and $350 \mathrm{~g}$, were fasted for $16-19 \mathrm{~h}$ prior to inducing diabetes mellitus with free access to water. A solution of streptozotocin (STZ) at $20 \mathrm{mg} / \mathrm{ml}$ in citrate buffer at $\mathrm{pH} 4.5$ was freshly prepared and used within $1 \mathrm{~h}$. Prior to injection, a drop of blood was collected from the tail vein to determine baseline blood glucose levels. Each rat was injected with a single intraperitoneal (i.p.) dose of STZ solution at $50 \mathrm{mg} / \mathrm{kg}, 48 \mathrm{~h}$ before the study. During the first $24 \mathrm{~h}$, rats were given $5 \%$ glucose to prevent hypoglycemia due to destruction of pancreatic $\beta$-cells. Fasted rats presenting a blood glucose level higher than $250 \mathrm{mg} / \mathrm{dl}$ were considered diabetic. Glucose was measured by using a Medisense ${ }^{\circledR}$ Precision Xtra glycometer (Abbott, Bedford, USA). Animal treatments were performed according to the Portuguese law (DL n. 197/96) and the institutional European guidelines (EEC n. 86/609).

\subsubsection{Determination of bioactivity of insulin}

In order to determine bioactivity of insulin during encapsulation procedure and microspheres recovery, $30 \mathrm{mg}$ of lyophilized 
microspheres were suspended in PBS $(10 \mathrm{ml})$ at $20^{\circ} \mathrm{C}$ for $2 \mathrm{~h}$. After centrifugation $(3000 \mathrm{rpm} / 2 \mathrm{~min}$ ) the supernatant was filtered through a $0.45 \mu \mathrm{m}$ pore size filter and the filtered solution was assayed for insulin content by HPLC, as described above. Blank microspheres, prepared without insulin, were treated in the same conditions and the supernatant used as negative control. The hypoglycemic effect was compared with that of rats given Actrapid $^{\circledR}(100 \mathrm{IU} / \mathrm{ml})$ dissolved in filtered PBS in order to obtain the same concentration achieved with insulin microspheres, used as positive control.

A dose of $4 \mathrm{IU} / \mathrm{kg}$ was injected subcutaneously into groups of eight diabetic rats fasted for at least $16 \mathrm{~h}$. Identical volumes of $1 \mathrm{ml} / \mathrm{kg}$ were used for the sample and positive and negative controls. Blood samples were collected from the tail vein after $30 \mathrm{~min}$ and $2 \mathrm{~h}$, corresponding to the onset and peak of action of regular insulin and assayed for blood glucose levels. After $24 \mathrm{~h}$, glycemia was measured to confirm the hyperglycemic state.

\subsubsection{Statistical analysis}

Each value was expressed as the mean \pm S.D. Statistical differences were analysed by using a one-way analysis of variance (ANOVA) followed by a Bonferroni post-test. For a value of $P<0.05$ the difference was considered significant.

\section{Results}

\subsection{Morphological and size characteristics}

Mean diameter values of alginate microspheres prepared using different process and formulation variables are presented in Tables 1 and 2, as well the standard deviation values related to the mean and the SPAN factor, which elucidate about the peak width. Microspheres mean diameter ranged from 21 to $288 \mu \mathrm{m}$ while changing process variables (Table 1). On the other hand,

Table 1

Effect of process variables on size distribution, insulin loading and encapsulation efficiency of microspheres

\begin{tabular}{|c|c|c|c|c|}
\hline & Mean size $(\mu \mathrm{m})$ & $\begin{array}{l}\text { SPAN } \\
\text { factor }\end{array}$ & $\begin{array}{l}\text { Insulin loading } \\
(\%, \mathrm{w} / \mathrm{w})\end{array}$ & $\begin{array}{l}\text { Encapsulation } \\
\text { efficiency }(\%, w / w)\end{array}$ \\
\hline \multicolumn{5}{|c|}{ Emulsifier concentration (\%) } \\
\hline 0 & $287.5 \pm 169.7$ & 1.74 & $4.17 \pm 0.05$ & $75.6 \pm 0.8$ \\
\hline 0.5 & $74.2 \pm 26.2$ & 0.96 & $4.09 \pm 0.04$ & $74.2 \pm 0.7$ \\
\hline $1.0^{\mathrm{a}}$ & $53.0 \pm 12.9$ & 0.66 & $4.18 \pm 0.10$ & $75.8 \pm 1.8$ \\
\hline \multicolumn{5}{|c|}{ Internal phase ratio (\%) } \\
\hline $30^{\mathrm{a}}$ & $53.0 \pm 12.9$ & 0.66 & $4.18 \pm 0.10$ & $75.8 \pm 1.8$ \\
\hline 40 & $41.7 \pm 26.6$ & 0.69 & $3.89 \pm 0.06$ & $70.5 \pm 1.1$ \\
\hline 50 & $26.6 \pm 6.9$ & 0.70 & $3.63 \pm 0.12$ & $65.8 \pm 2.2$ \\
\hline \multicolumn{5}{|c|}{ Impeller rotational speed (rpm) } \\
\hline 200 & $188.5 \pm 149.0$ & 2.19 & $3.93 \pm 0.08$ & $71.3 \pm 1.5$ \\
\hline $400^{\mathrm{a}}$ & $53.0 \pm 12.9$ & 0.66 & $4.18 \pm 0.10$ & $75.8 \pm 1.8$ \\
\hline 600 & $21.2 \pm 6.5$ & 0.78 & $4.06 \pm 0.04$ & $73.6 \pm 0.6$ \\
\hline
\end{tabular}

Microspheres were prepared by using the standard conditions. Data are shown as mean \pm S.D

a Standard preparation conditions.
Table 2

Effect of formulation variables on size distribution, insulin loading and encapsulation efficiency of microspheres

\begin{tabular}{lccll}
\hline & Mean size $(\mu \mathrm{m})$ & $\begin{array}{l}\text { SPAN } \\
\text { factor }\end{array}$ & $\begin{array}{l}\text { Insulin loading } \\
(\%, w / w)\end{array}$ & $\begin{array}{l}\text { Encapsulation } \\
\text { efficiency }(\%, w / w)\end{array}$ \\
\hline Ca/alginate ratio $(\%, w / w)$ & & & \\
5.0 & $61.9 \pm 18.5$ & 0.80 & $3.87 \pm 0.20$ & $70.1 \pm 3.6$ \\
6.0 & $61.2 \pm 15.0$ & 0.67 & $3.65 \pm 0.12$ & $66.2 \pm 2.3$ \\
$7.3^{\mathrm{a}}$ & $53.0 \pm 12.9$ & 0.66 & $4.18 \pm 0.10$ & $75.8 \pm 1.8$ \\
8.7 & $45.6 \pm 13.8$ & 0.77 & $3.90 \pm 0.02$ & $70.8 \pm 0.3$ \\
10.0 & $55.2 \pm 16.2$ & 0.80 & $3.61 \pm 0.02$ & $65.5 \pm 0.4$ \\
16.7 & $48.8 \pm 11.5$ & 0.64 & $3.60 \pm 0.05$ & $65.3 \pm 1.0$ \\
Acid/Ca molar ratio & & & \\
1.5 & $55.3 \pm 15.9$ & 0.79 & $3.58 \pm 0.10$ & $64.9 \pm 1.8$ \\
2.0 & $47.3 \pm 11.5$ & 0.66 & $3.96 \pm 0.07$ & $71.8 \pm 1.3$ \\
$3.5^{\mathrm{a}}$ & $53.0 \pm 12.9$ & 0.66 & $4.18 \pm 0.10$ & $75.8 \pm 1.8$ \\
Alginate concentration $(\%, \mathrm{w} / \mathrm{v})$ & & \\
$2.0^{\mathrm{a}}$ & $53.0 \pm 12.9$ & 0.66 & $4.18 \pm 0.10$ & $75.8 \pm 1.8$ \\
2.5 & $97.1 \pm 44.3$ & 1.32 & $3.44 \pm 0.07$ & $77.2 \pm 1.5$ \\
3.0 & $112.2 \pm 79.1$ & 1.77 & $2.91 \pm 0.10$ & $77.9 \pm 2.8$ \\
Zn/insulin hexamer ratio & & & \\
$2.0^{\mathrm{a}}$ & $53.0 \pm 12.9$ & 0.66 & $4.18 \pm 0.10$ & $75.8 \pm 1.8$ \\
5.5 & $46.4 \pm 11.4$ & 0.67 & $4.13 \pm 0.07$ & $75.0 \pm 1.3$ \\
9.0 & $46.4 \pm 12.9$ & 0.75 & $4.37 \pm 0.07$ & $79.2 \pm 1.3$ \\
13.0 & $45.4 \pm 12.1$ & 0.72 & $4.09 \pm 0.07$ & $74.2 \pm 1.4$ \\
\hline
\end{tabular}

Microspheres were prepared by using the standard conditions. Data are shown as mean \pm S.D.

${ }^{\text {a }}$ Standard preparation conditions

altering the formulation variables caused mean diameter to vary from 45 to $112 \mu \mathrm{m}$ (Table 2).

All the studied process variables had influence on the mean diameter, especially the emulsifier concentration and the mixer rotational speed. An increase in the emulsifier concentration resulted in a decrease in the microspheres mean size from 288 to $53 \mu \mathrm{m}$. For microspheres prepared with $0.5 \%$ and without emulsifier, standard deviations of the mean diameter were 35 and $59 \%$, respectively, while in the case of microspheres prepared with $1 \%$ of emulsifier a lower standard deviation of $24 \%$ was obtained. Microspheres polydispersity obtained from the calculation of SPAN factor agreed with relative standard deviation results since values decreased from 1.74 to 0.66 when the emulsifier concentration was increased. Increasing the mixer rotational speed from 200 to $600 \mathrm{rpm}$ resulted in a nine-fold decrease in microspheres mean size (Fig. 1). The SPAN factor for microspheres prepared at $400 \mathrm{rpm}$ was 0.66 , but when the mixer speed was changed, either to 200 or $600 \mathrm{rpm}$, higher values of 2.19 and 0.78 were, respectively, achieved. On the other hand, an increase on the internal/external phase ratio during the emulsification step from 30 to $50 \%$, while keeping total liquid volume constant, led to a decrease in microspheres mean size from 53 to $27 \mu \mathrm{m}$. Nevertheless polydispersity was not altered since the SPAN factor values were very similar.

Within formulation parameters only alginate concentration affected mean size. When alginate concentration was increased from 2 to $3 \%(\mathrm{w} / \mathrm{v})$ the particle diameter increased from 53 


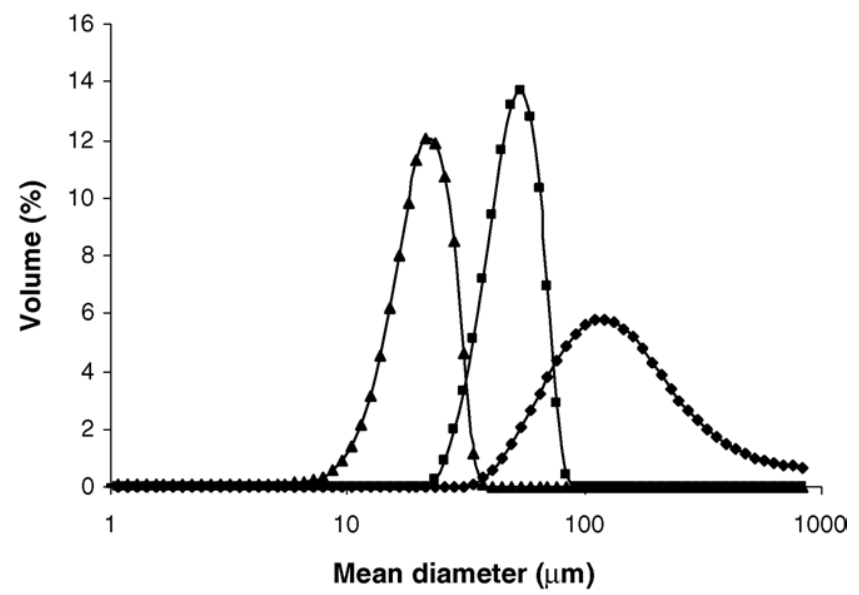

Fig. 1. Volume size distribution of microspheres formed at different mixer rotational speed: $200 \mathrm{rpm}(\diamond), 400 \mathrm{rpm}(\mathbf{\square})$ and $600 \mathrm{rpm}(\boldsymbol{\Delta})$. Microspheres were prepared by using the standard conditions.

to $112 \mu \mathrm{m}$ and this increase in size was accompanied with an increase in SPAN factor from 0.66 to 1.77. Concentrations of alginate above $3 \%$ were assayed however microspheres manufacturing became difficult due to the increase in the viscosity of alginate solution.

$\mathrm{Ca} /$ alginate mass ratio and acid/Ca molar ratio, parameters influencing the gelation characteristics of the polymer, did not appear to influence mean size of microspheres. However, decreasing $\mathrm{Ca} /$ alginate ratio $(\mathrm{w} / \mathrm{w})$ caused a slight increase on mean size.

During the aqueous phase preparation, before the emulsification step of microspheres preparation, insulin was diluted in water or zinc acetate solution at different concentrations, in order to obtain $\mathrm{Zn} /$ insulin hexamer ratios ranging from 2.0 to 13.0 but mean size and size distribution were not considerably altered by this parameter.

Regardless of size variations occurring by changing process and formulation variables, microspheres were always disperse and spherical as illustrated in Fig. 2a and no aggregation of microspheres was observed. Tubular and star-like structures

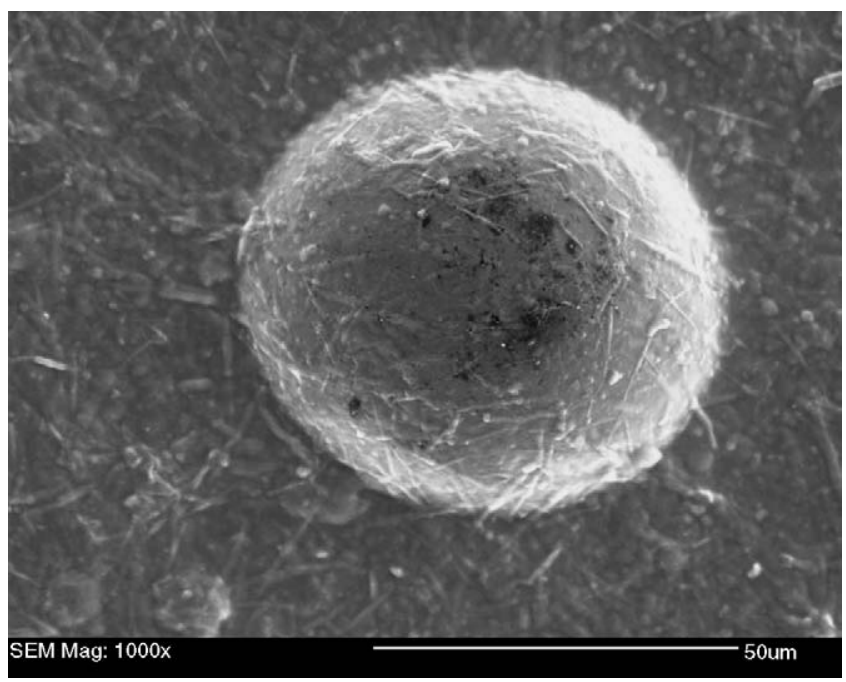

Fig. 3. Morphology and size of insulin-loaded alginate microspheres according to SEM micrograph (magnification $1000 \times$ ) prepared by using the standard conditions.

were visible in the microspheres and attributed to the presence of insulin, since they were not present in blank microspheres prepared without insulin (Fig. 2b). SEM micrograph (Fig. 3) confirmed this observation showing a smooth surface on which the mentioned tubules were present.

\subsection{Encapsulation efficiency}

The analysis of insulin content and encapsulation efficiency within microspheres prepared using different process and formulation parameters are reported in Tables 1 and 2, respectively. Emulsifier concentration and mixer rotational speed did not affect encapsulation efficiency of insulin inside microspheres $(P>0.05)$, while increasing internal phase volume from 30 to $50 \%$ led to a significant decrease of $10 \%(P<0.001)$ in encapsulation efficiency. Insulin loading varied proportionally to encapsulation efficiency since the drug/polymer ratio was maintained constant.
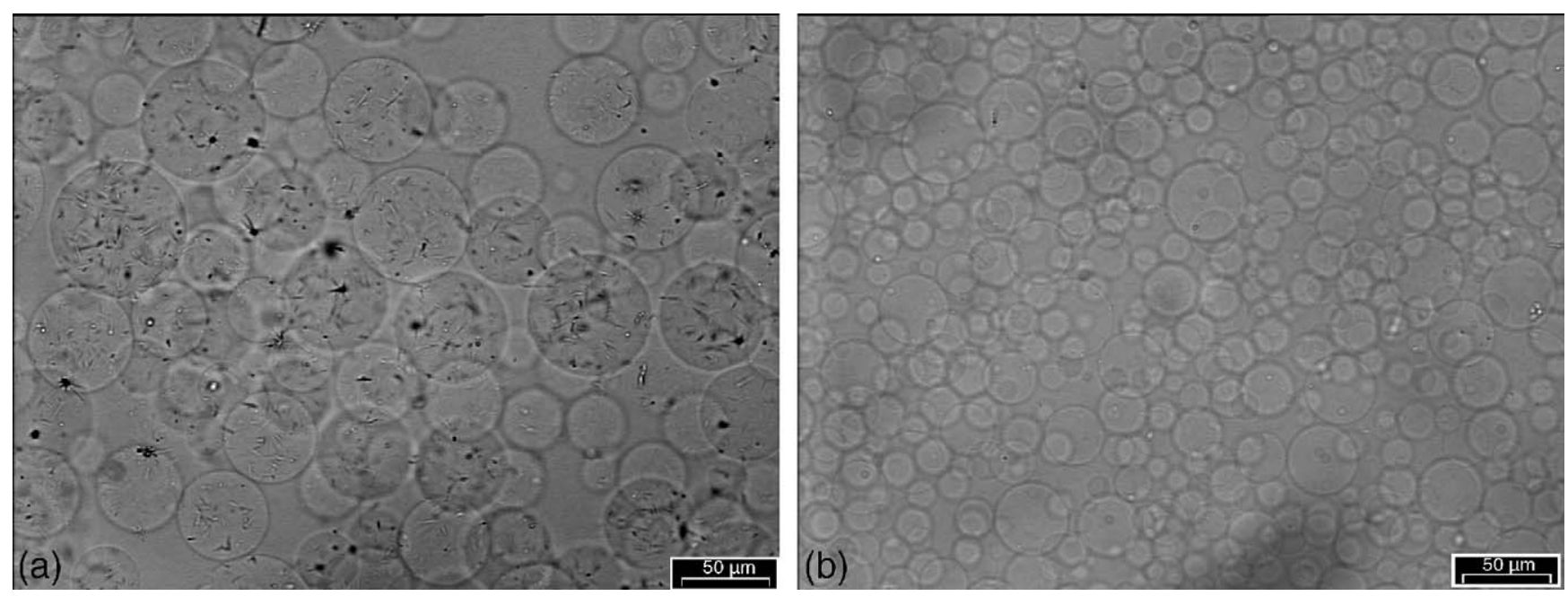

Fig. 2. Optical microphotograph of insulin-loaded (a) and blank (b) alginate microspheres (magnification $200 \times$ ) prepared by using the standard conditions. 
In respect to formulation parameters, values of encapsulation efficiency varied from 65 to $79 \%$ and were especially affected by parameters influencing alginate gelation, such as $\mathrm{Ca}$ /alginate mass ratio and acid/Ca molar ratio. No systematic effect of $\mathrm{Ca} /$ alginate mass ratio was observed, but higher efficiency was obtained with a $\mathrm{Ca}$ /alginate ratio of $7.3 \%$ and then increasing the proportion of $\mathrm{Ca}^{2+}$ resulted in significantly lower values $(P<0.001)$. In the case of acid/Ca molar ratio, the encapsulation efficiency decreased from 76 to $65 \%(P<0.05)$ by decreasing the proportion of acid from 3.5 to 1.5 .

Raising alginate concentration from 2 to $3 \%$ did not cause significant changes on insulin encapsulation efficiency $(P>0.05)$. On the contrary, a decrease in insulin loading from 4.2 to $2.9 \%$ was obtained, due to a higher polymer/drug ratio.

Increasing $\mathrm{Zn} / \mathrm{h}$ examer ratio from 2.0 to 5.5 or $13.0 \mathrm{did}$ not change the protein encapsulation; however a $\mathrm{Zn} /$ hexamer ratio of 9.0 increased insulin encapsulation in microspheres.

\subsection{Insulin release}

Under simulated gastric $\mathrm{pH}$, insulin-loaded alginate microspheres presented a high protein release, near $80 \%$ (Fig. 4), independently of process or formulation variables used, with exception to alginate concentration. A fast and almost total insulin release, reaching $75 \%$, occurred within 5 min followed by a slow release which led to a total cumulative release of $80 \%$. After changing to intestinal $\mathrm{pH}$, a fast and complete dissolution of microspheres occurred, permitting an immediate total insulin release. It is important to note that increasing alginate concentration caused a slightly higher retention of protein at $\mathrm{pH}$ 1.2. Insulin release in acidic medium decreased from 81.9 to 77.8 and $73.8 \%$ when alginate concentration increased from 2 to 2.5 and 3\% (data not shown), however a complete dissolution was also observed after transferring microspheres to intestinal $\mathrm{pH}$. Nevertheless, due to the higher viscosity of alginate solution, manufacture becomes difficult with concentrations higher than $2.5 \%$.

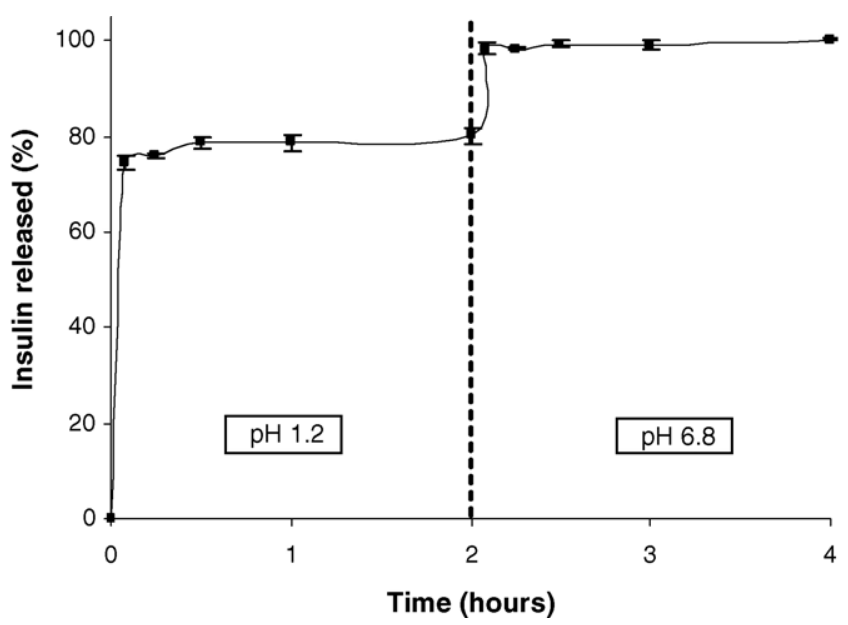

Fig. 4. In vitro release profile of insulin from microspheres prepared following the standard conditions and incubated in simulated gastric fluid for $2 \mathrm{~h}$ and then in simulated intestinal fluid. The results are the mean of three experiments \pm S.D.

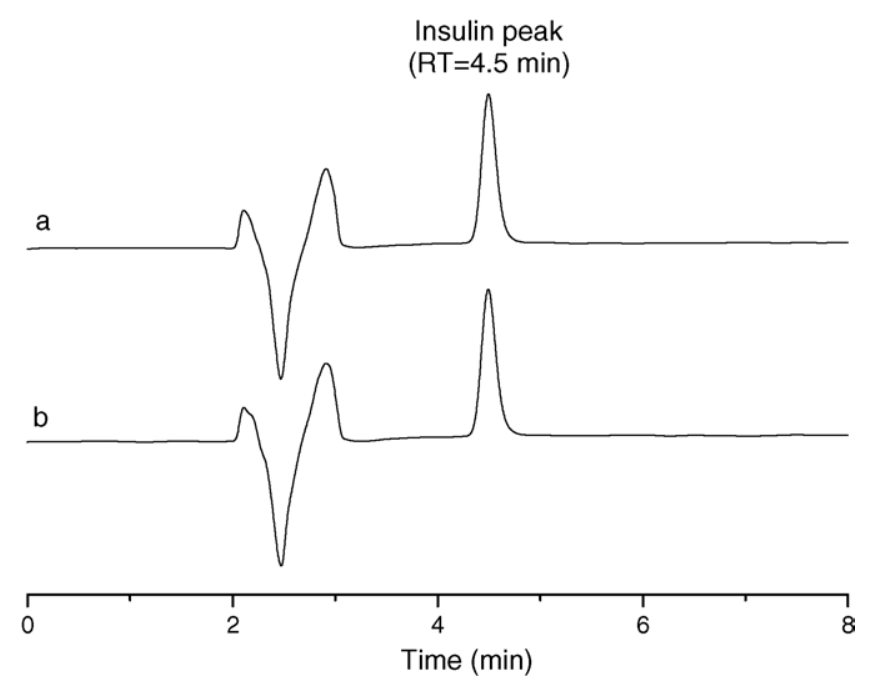

Fig. 5. HPLC chromatograms of (a) insulin released from alginate microspheres after incubation in PBS and (b) insulin standard.

\subsection{Bioactivity of insulin}

The chromatogram of insulin released from microspheres after incubation in PBS had identical retention time to the insulin standard and no transformation products were detected (Fig. 5), such as the A21 desamido-insulin, which suggested the maintenance of insulin stability after microsphere manufacture, recovery and lyophilization (Jiang et al., 2003). Nevertheless, the bioactivity was evaluated in vivo by subcutaneously injecting the insulin released from microspheres after incubation in PBS. The serum glucose concentration of the STZ-induced diabetic rats decreased to a normal level $(<120 \mathrm{mg} / \mathrm{dl})$ within $30 \mathrm{~min}$ after administration of the solution (Fig. 6). A further decrease was obtained $2 \mathrm{~h}$ after administration reaching approximately $10 \%$ of the initial blood glucose levels. This behaviour was similar for the rats injected with Actrapid $^{\circledR}$ as a positive control. The differences between extracted insulin and Actrapid ${ }^{\circledR}$ were not significant for both sampling withdrawal times $(P=0.263$ and

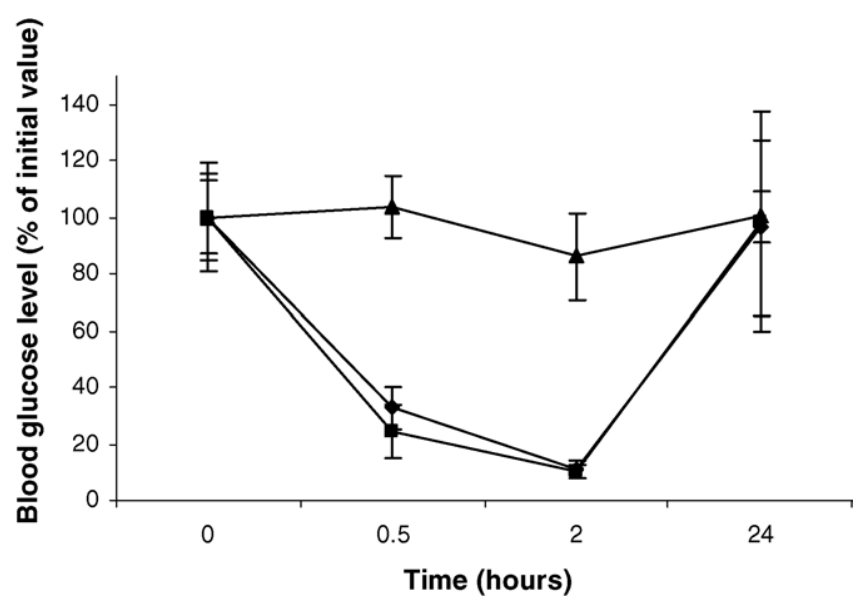

Fig. 6. Effect of insulin injected subcutaneously to STZ-induced diabetic rats on blood glucose levels: $(\boldsymbol{\Lambda})$ control, $(\boldsymbol{\square})$ Actrapid ${ }^{\circledR}$ formulation and $(\boldsymbol{\vee})$ insulin extracted from alginate microspheres. The results are the mean of eight experiments \pm S.D. 
0.457 for $30 \mathrm{~min}$ and $2 \mathrm{~h}$, respectively). The negative control group, which was given the solution obtained after incubation of blank microspheres in PBS, exhibited hyperglycemia.

\section{Discussion}

\subsection{Formulation optimization}

The emulsification/internal gelation method, used in this study, prevented the aggregation of microspheres even when no emulsifier was added to the water/oil emulsion. The aggregation phenomenon was reported for alginate microspheres obtained by emulsification/external gelation (Wan et al., 1993) due to the addition of calcium chloride to the water/oil emulsion, which may induce the disruption of the emulsion system equilibrium (Chan et al., 2002). In the internal gelation method only a small volume of oil-soluble acid previously dispersed in paraffin oil is added, which should not affect emulsion stability. Besides, in our study, mineral oil was used as lipophilic phase instead of iso-octane that presents lower viscosity. When oil viscosity increases, microspheres size decreases which decreases surface tension and increases emulsion stability. We do believe that one of these factors or the combination of both may justify the absence of aggregation, using the emulsification/internal gelation method.

In this study, size distribution of microspheres presented unimodal distribution with no secondary peaks, which have been reported by using the same method (Poncelet et al., 1995; Tin et al., 1997). In order to obtain unimodal distribution of microspheres, which allows a better control of drug kinetics, some strategies like the membrane emulsification/internal gelation method (Liu et al., 2003) were developed. However, using the method presented in this study, an identical mean diameter and SPAN factor were obtained.

The size distribution of the recovered microspheres obtained by emulsification/internal gelation is correlated with the size distribution of the emulsion droplets. The average size of droplets is determined by various parameters such as apparatus design, viscosity of the two immiscible phases and speed of mixing. A qualitative equation (Eq. (1)) has been proposed as guide for controlling the size of microspheres (Arshady, 1990):

$\bar{d} \propto K \frac{D_{\mathrm{V}} R v_{\mathrm{d}} \gamma}{D_{\mathrm{S}} N v_{\mathrm{m}} C_{\mathrm{s}}}$

where $\bar{d}$ is the average droplet (particle) size, $K$ symbolizes parameters such as apparatus design, type of stirrer, self stabilization, $D_{\mathrm{V}}$ the diameter of the vessel, $D_{\mathrm{S}}$ the diameter of the stirrer, $R$ the volume ratio of the droplet phase to suspension medium, $N$ the stirring speed, $v_{\mathrm{d}}$ the viscosity of the droplet phase, $v_{\mathrm{m}}$ the viscosity of the suspension medium, $\gamma$ the surface tension between the two immiscible phases and $C_{\mathrm{s}}$ is the stabilizer concentration. In this study, parameters related to the vessel and stirrer characteristics were made constant. Also, the viscosity of suspension medium was not altered since the same paraffin oil was used in all formulations.
Accordingly, to Eq. (1), diameter distribution decreases by increasing emulsifier concentration, which decreases the interfacial tension between the alginate droplets and the oil in the continuous phase. The surfactant is expected to promote the stability of the w/o emulsion and, in fact, size was reduced in the presence of $\operatorname{Span}^{\circledR}$ 80. The encapsulation efficiency was not affected by this parameter although it could be expected that factors favouring the increase of mean size could increase encapsulation efficiency due to a reduced surface area. Based in these results, the highest concentration of emulsifier (1\%) that led to the lowest size was chosen.

The effect of higher stirring speed on microsphere mean diameter, contributing to a higher heterogeneity of the batch may be caused by the distribution of turbulent forces throughout the emulsion (Lim et al., 1997). Since, shear stress is higher at the tip of the propeller than at the centre, a faster stirring speed increased this difference, thereby providing a less uniform distribution of energy and giving rise to microspheres of a wider size distribution. Thus, an impeller rotational speed of $400 \mathrm{rpm}$ was chosen to allow the achievement of small microspheres with a narrow size distribution. Moreover, protein drugs are susceptible to denaturation when they are submitted to high shear forces (Shively, 1997).

Increasing the internal phase ratio from 30 to $50 \%$ led to a decrease on microspheres mean size, which disagrees with Eq. (1) and other studies (Tin et al., 1997; Li et al., 1999; Moslemy et al., 2002) where it was verified that a higher proportion of dispersed phase produce an overall increase in mean size, justified by an increase in the frequency of collisions during emulsification, resulting in the formation of aggregates. Previously it was verified, during hemoglobin encapsulation, that increasing internal phase ratio resulted in a slight decrease in the mean size (Silva et al., 2005) and, in this study, using the same methodology, these differences were further evidenced. The decrease in mean size was associated with a decrease in insulin encapsulation, not observed when emulsifier concentration and stirring speed were changed. One possible explanation is that when aqueous/oil phase proportion changes, the oil barrier against protein loss may become less significant for a higher internal phase ratio. Thus, a $30 \%$ ratio was chosen for the standard formulation, because the effect of internal/external phase ratio on the encapsulation efficiency was considered more important comparatively to the mean size of microspheres.

It is difficult to establish a frontier between process and formulation variables, for example, alginate concentration is a formulation variable that also may be considered as a process variable, since increasing alginate concentration increases the viscosity of the internal phase during the emulsification step and a higher energy level is necessary to disperse high viscosity solutions. Contrary to the expected effect of alginate concentration on microspheres mean size and peak width, related to a higher resistance to the dispersive forces in the emulsification step and reduction on the efficiency of stirring, no important effect of this parameter on insulin encapsulation was found.

Parameters directly related to the gelation characteristics of the polymer, such as $\mathrm{Ca}$ /alginate mass ratio and acid/Ca molar ratio, did not present great influence on mean size of 
microspheres. The slight decrease in particle size observed when higher $\mathrm{Ca}$ /alginate mass ratio was used may be due to a more extensive gel shrinkage because more calcium is available for gelation (Ostberg et al., 1993). It is well established that calcium-alginate gels shrink during gel formation due to water loss (Martinsen et al., 1989).

In the case of increased acid/Ca molar ratio a similar effect could be expected since the acid is responsible for calcium release. Considering the reaction between acetic acid and calcium carbonate, each mole of $\mathrm{CaCO}_{3}$ reacts with 2 mol of $\mathrm{CH}_{3} \mathrm{COOH}$. When an acid/Ca molar ratio of 1.5 was used the amount of acetic acid was insufficient to dissolve all the amount of $\mathrm{CaCO}_{3}$ added to alginate solution, since it was below the stoichiometric proportion. However, it is thought that, as microspheres are recovered in acetate buffer at $\mathrm{pH} 4.5$, the undissolved calcium carbonate that may exist inside the microspheres is dissolved and the effect of acetic acid/Ca molar ratio is imperceptible.

$\mathrm{Ca}$ alginate molar ratio influenced significantly encapsulation efficiency of insulin. It was observed (Poncelet, 2001), that a $\mathrm{Ca}$ /alginate monomer ratio of $1 / 4$ (corresponding to a $5 \% \mathrm{Ca}$ /alginate mass ratio $\mathrm{w} / \mathrm{w}$ ) was sufficient to ensure strong microsphere formation however, in this study, we found that a higher encapsulation efficiency of insulin was obtained with a $\mathrm{Ca}$ /alginate ratio of $7.3 \%$ and that calcium ions should not be in a high excess, in relation to alginate, which permits to conclude that alginate degree of gelation was fundamental for the retention of protein inside microspheres. An increase in calcium concentration was shown to reduce drug encapsulation efficiency explained by higher degree of gel shrinkage in more concentrated calcium chloride solution (Ostberg et al., 1993), however in our study the decrease in insulin encapsulation was not accompanied with a proportional decrease in size.

The increase of encapsulation efficiency with increasing acid/Ca molar ratio is explained by an increased availability of calcium permitting a higher extent of alginate gelation (Amsden and Turner, 1999) that led to stronger microspheres, providing a greater resistance to solute transport (Ostberg et al., 1994). Based on this results a ratio of 3.5 was selected for the optimal formulation.

Sodium alginate was dissolved in zinc acetate solution to study the influence of zinc ion on insulin encapsulation efficiency, however the polymer is able to complex with zinc, although the association is weaker than with calcium (Aslani and Kennedy, 1996). This interaction between alginate and zinc could result in a pre-gelation of alginate solution before emulsification with an increase in its viscosity and a, subsequently, increase in internal phase droplets mean size. Nevertheless, the properties of the alginate solution were not significantly altered before the emulsification step probably due to the low $\mathrm{Zn}$ concentrations employed.

Actrapid formulation is a stable neutral solution containing approximately two $\mathrm{Zn}$ atoms per insulin hexamer. Using water to dilute the Actrapid formulation $(2: 1, \mathrm{v} / \mathrm{v})$ the $\mathrm{Zn} / \mathrm{hexamer}$ molar ratio of 2.0 is maintained. Alternatively, Actrapid was diluted in zinc acetate solution at different concentrations to change that ratio and decrease insulin solubility, so that encapsu- lation efficiency could increase. In solutions of insulin at $\mathrm{pH} 7.0$ with two zinc ions per six monomers of insulin, the hexameric form comprises $75 \%$ or more of total insulin at a concentration above $100 \mu \mathrm{g} / \mathrm{ml}$. The $\mathrm{Zn}$-insulin complexes are soluble when the $\mathrm{Zn} /$ insulin (hexameric) ratio is below 4, but at higher concentrations of zinc the solubility decreases and when a ratio of 6 is reached complete precipitation of insulin is observed (Brange et al., 1987). Actrapid ${ }^{\circledR}$ was diluted in zinc acetate (ZnAc) at different concentrations to change $\mathrm{Zn}$ /hexamer molar ratio and possibly decrease insulin solubility, so that encapsulation efficiency could increase. This hypothesis was verified when $\mathrm{Zn} /$ hexamer ratio was increased to 9.0 but the decrease on insulin encapsulation observed for a 13.0 ratio did not confirm it. Therefore a ratio of 9.0 was chosen for the optimal formulation.

The influence of zinc ions on insulin encapsulation efficiency in alginate microspheres has been previously studied (Gray and Dowsett, 1988). It was found that when zinc ions are present in the processing medium, insulin is substantially retained. The concentrations of zinc chloride ranged from 0.08 to $0.26 \mathrm{M}$, values that were substantially higher than those used in this study. The zinc ions, at these concentrations, could effectively interact with alginate reducing the pore size of alginate gel, but could also bind to insulin and form bridges between the protein molecules and the alginate matrix.

Microspheres produced by emulsification/internal gelation using the chosen values for the different process and formulation parameters showed an unimodal size distribution with a mean diameter of $53 \mu \mathrm{m}$ and an encapsulation efficiency of insulin near $79 \%$. The insulin content of $4.4 \%$ (w/w), corresponding to approximately $1.3 \mathrm{IU} / \mathrm{mg}$ of microspheres, is much higher than those obtained by the encapsulation of the same protein either in chitosan-coated alginate microspheres (Moses et al., 2000) or liposomes further encapsulated in alginate-chitosan microspheres (Ramdas et al., 2000), 11.0 and 21.5 IU/g of alginate, respectively.

\subsection{Insulin release}

The effect of $\mathrm{pH}$ on $\mathrm{Ca}$-alginate hydrogels network structure has been neglected. Microspheres incubation, at pH 1.2, causes calcium ions to be displaced from the polymer network and the calcium-alginate gel is converted to the unionized form of alginic acid. After this acid treatment, even if calcium ions do not contribute anymore to the stabilization of the microspheres, the microspheres maintain their macroscopic structure without any visible changes in the morphology (Fundueanu et al., 1999; Zhou et al., 2001), explained by the formation of hydrogen bonds which give a stable structure (Doumèche et al., 2004). This may lead to dissociation of ionic linkages and reduction in the gel strength that may favour drug release by diffusion (Ostberg et al., 1994).

The observed burst release of insulin may be related to the weak retention of alginate structure. Besides, protein molecules dispersing close to the microspheres surface diffuse out during the initial incubation time. In addition, insulin monomers exhibit hydrophobic regions at the surface of the molecule, 
which could favour interaction with the external oily phase during emulsification and the localization of insulin at the surface of microspheres after recovery. As the $\mathrm{pH}$ was changed to 6.8 , the alginic acid was converted to a soluble salt of sodium alginate and the matrix disintegrated, completely releasing the insulin that was left in microspheres.

Insulin release in acidic media is not compatible with the susceptibility of the protein to enzymatic attack. For this reason, the formulation needs to be improved and studies are already on going concerning the inclusion of other polymers in the alginate matrix to prevent insulin release at acidic $\mathrm{pH}$.

\subsection{Bioactivity}

In the emulsification/internal gelation method there is no heat and the mechanical stress is limited since a stirring speed of only $400 \mathrm{rpm}$ was selected. However, the presence of an air-water or a water-oil interface, formed during emulsification, may lead to aggregation and fibril formation of an aqueous solution of insulin (Sluzky et al., 1991). The protein must maintain intact its three-dimensional structure and chemical integrity during the encapsulation process to allow the delivery of the native protein upon administration (Cleland, 1997). When emulsions are prepared, the total interfacial area increases as the droplet size decreases but it was observed that the exposure to the oil-water interface combined with the mechanical stress of manufacture is not quite as harsh a treatment as simple shaking and exposure to the air-solution interface (Jorgensen et al., 2003). Furthermore, a better protection of the protein from exposure to interfaces may be obtained by addition of surfactants due either to a steric effect which blocks aggregation-prone hydrophobic sites on the protein surface (Bam et al., 1998) or to a competitive effect with the protein for space at the surface, thereby, preventing part of the protein from reaching the interface and the subsequent adsorption and structural perturbation (Jorgensen et al., 2004). This may explain the preservation of insulin stability during microspheres preparation, suggesting that emulsification/internal gelation is appropriate for the encapsulation of proteins.

Moreover, it was possible the development of interactions between insulin and alginate since microspheres were recovered with acetate buffer at $\mathrm{pH} 4.5$. This buffer was chosen to increase insulin encapsulation efficiency based on the fact that, at this $\mathrm{pH}$ value, alginate and insulin $(\mathrm{p} I=5.3)$ have opposite charges. However, since insulin extracted from microspheres produced the same bioavailability as short-acting insulin formulation, this interaction should be reversible and not interfere with protein structural integrity.

\section{Conclusion}

This study showed that it is possible to produce insulinloaded alginate microspheres intended for oral administration using the emulsification/internal gelation method. Mean diameter was less than $60 \mu \mathrm{m}$ and an encapsulation efficiency of near $75 \%$ was obtained. Process and formulation variables were of utmost importance for size and encapsulation properties.
The size of microspheres was mainly determined by process parameters such as emulsifier concentration and stirring speed. $\mathrm{Ca} /$ alginate mass ratio and acid/Ca molar ratio significantly influenced insulin encapsulation. Calcium ions should not be insufficient in relation to alginate nor be in a high excess, and the amount of acid should be enough to solubilize calcium carbonate, which permits to conclude that alginate degree of gelation is fundamental for the retention of protein inside microspheres.

Encapsulated insulin produced the same bioavailability in diabetic rats as short-acting insulin formulation showing that insulin integrity was maintained during microspheres manufacturing and recovery. However, at gastric $\mathrm{pH}$, a high protein release was obtained and further studies should be conducted to improve this result.

\section{Acknowledgements}

The authors would like to thank Eng. Vítor Redondo and Dr. Margarida Figueiredo for technical support and for providing the facilities to perform size distribution determination. This research was financially supported by a grant from the "Fundação para a Ciência e Tecnologia" (FCT) of Portugal (SFRH/BD/5085/2001).

\section{References}

Agarwal, V., Reddy, I.K., Khan, M.A., 2001. Polymethyacrylate based microparticulates of insulin for oral delivery: preparation and "in vitro" dissolution stability in the presence of enzyme inhibitors. Int. J. Pharm. 225, 31-39

Albarghouthi, M., Fara, D.A., Saleem, M., El-Thaher, T., Matalka, K., Badwan, A., 2000. Immobilization of antibodies on alginate-chitosan beads. Int. J. Pharm. 206, 23-34.

Amsden, B., Turner, N., 1999. Diffusion characteristics of calcium alginate gels. Biotechnol. Bioeng. 65, 605-610.

Arshady, R., 1990. Albumin microspheres and microcapsules: methodology of manufacturing techniques. J. Control. Rel. 14, 111-131.

Aslani, P., Kennedy, R.A., 1996. Studies on diffusion in alginate gels. I. Effect of cross-linking with calcium or zinc ions on diffusion of acetaminophen. J. Control. Rel. 42, 75-82.

Bam, N.B., Cleland, J.L., Yang, J., Manning, M.C., Carpenter, J.F., Kelley, R.F., Randolph, T.W., 1998. Tween protects recombinant human growth hormone against agitation-induced damage via hydrophobic interactions. J. Pharm. Sci. 87, 1554-1559.

Boadi, D.K., Neufeld, R.J., 2001. Encapsulation of tannase for the hydrolysis of tea tannins. Enz. Microbial Technol. 28, 590-595.

Brange, J., Langkjaer, L., 1997. Insulin formulation and delivery. In: Sanders, L.M., Hendren, R.W. (Eds.), Protein Delivery: Physical Systems. Plenum Press, New York, pp. 343-410.

Brange, J., Skelbaek-Pedersen, B., Langkjaer, L., Damgaard, U., Ege, H., Havelund, S., Heding, L.G., Jorgensen, K.H., Lykkeberg, J., Markussen, J., Pingel, M., Rasmussen, E., 1987. Galenics of Insulin: The Physicochemical and Pharmaceutical Aspects of Insulin and Insulin Preparations. Springer-Verlag, Berlin, Heidelberg, New York, London, Paris, Tokyo.

Chan, L.W., Lee, H.Y., Heng, P.W.S., 2002. Production of alginate microspheres by internal gelation using an emulsification method. Int. J. Pharm. 242, 259-262.

Chickering, D.E., Jacob, J.S., Desai, T.A., Harrison, M., Harris, W.P., Morrell, C.N., Chaturvedi, P., Mathiowitz, E., 1997. Bioadhesive microspheres: III. "In vivo" transit and bioavailability study of drug-loaded alginate and poly(fumaric-co-sebacic anhydride) microspheres. J. Control. Rel. 48, $35-46$. 
Cleland, J.L., 1997. Protein delivery from biodegradable microspheres. In: Sanders, L.M., Hendren, R.W. (Eds.), Protein Delivery: Physical Systems. Plenum Press, New York, pp. 1-43.

Cleland, J.L., Daugherty, A., Mrsny, R., 2001. Emerging protein delivery methods. Curr. Opin. Biotechnol. 12, 212-219.

Coppi, G., Iannuccelli, V., Leo, E., Bernabei, M.T., Cameroni, R., 2002. Protein immobilization in crosslinked alginate microparticles. J. Microencapsul. 19, 37-44.

Damge, C., Michel, C., Aprahamian, M., Couvreur, P., 1988. New approach for oral administration of insulin with polyalkylcyanoacrylate nanocapsules as drug carrier. Diabetes 37, 246-251.

Doumèche, B., Kuppers, M., Stapf, S., Blumich, B., Hartmeier, W., AnsorgeSchumacher, M.B., 2004. New approaches to the visualization, quantification and explanation of acid-induced water loss from Ca-alginate hydrogel beads. J. Microencapsul. 21, 565-573.

El-Mahdy, M., Ibrahim, E.S., Safwat, S., El-Sayed, A., Ohshima, H., Makino, K., Muramatsu, N., Kondo, T., 1998. Effects of preparation conditions on the monodispersity of albumin microspheres. J. Microencapsul. 15, 661-673.

Fundueanu, G., Nastruzzi, C., Carpov, A., Desbrieres, J., Rinaudo, M., 1999. Physico-chemical characterization of $\mathrm{Ca}$-alginate microparticles produced with different methods. Biomaterials 20, 1427-1435.

Gray, C.J., Dowsett, J., 1988. Retention of insulin in alginate gel beads. Biotechnol. Bioeng. 31, 607-612.

Hari, P.R., Chandy, T., Sharma, C.P., 1996. Chitosan/calcium-alginate beads for oral delivery of insulin. J. Appl. Polym. Sci. 59, 1795-1801.

Jerry, N., Anitha, Y., Sharma, C.P., Sony, P., 2001. "In vivo" absorption studies of insulin from an oral delivery system. Drug Deliv. 8, 19-23.

Jiang, G., Qiu, W., DeLuca, P.P., 2003. Preparation and "in vitro"/“in vivo" evaluation of insulin-loaded poly(acryloyl-hydroxyethyl starch)-PLGA. Pharm. Res. 20, 452-459.

Jorgensen, L., Kim, D.H., Vermehren, C., Bjerregaard, S., Frokjaer, S., 2004. Micropipette manipulation: a technique to evaluate the stability of waterin-oil emulsions containing proteins. J. Pharm. Sci. 93, 2994-3003.

Jorgensen, L., Vermehren, C., Bjerregaard, S., Froekjaer, S., 2003. Secondary structure alterations in insulin and growth hormone water-in-oil emulsions. Int. J. Pharm. 254, 7-10.

Klinkenberg, G., Lystad, K.Q., Levine, T.D.W., Dyrset, N., 2001. Cell release from alginate immobilized Lactococcus lactis ssp. lactis in chitosan and alginate coated beads. J. Dairy Sci. 84, 1118-1127.

Li, X., Deng, X., Yuan, M., Xiong, C., Huang, Z., Zhang, Y., Jia, W., 1999. Investigation on process parameters involved in preparation of poly-DL-lactide-poly(ethylene glycol) microspheres containing Leptospira Interrogans antigens. Int. J. Pharm. 178, 245-255.

Li, X., Zhang, Y., Yan, R., Jia, W., Yuan, M., Deng, X., Huang, Z., 2000. Influence of process parameters on the protein stability encapsulated in poly-DL-lactide-poly(ethylene glycol) microspheres. J. Control. Rel. 68, 41-52.

Lim, L.Y., Wan, L.S., Thai, P.Y., 1997. Chitosan microspheres prepared by emulsification and ionotropic gelation. Drug Dev. Ind. Pharm. 23, 981-985.

Liu, X.D., Bao, D.C., Xue, W.M., Xiong, Y., Yu, W.T., Yu, X.J., Ma, X.J., Yuan, Q., 2003. Preparation of uniform calcium alginate gel beads by membrane emulsification coupled with internal gelation. J. Appl. Polym. Sci. 87, 848-852.

Lowman, A.M., Morishita, M., Kajita, M., Nagai, T., Peppas, N.A., 1999. Oral delivery of insulin using $\mathrm{pH}$ responsive complexation gels. J. Pharm. Sci. 88, 933-937.
Martinsen, A., Skjak Braek, G., Smidsrod, O., 1989. Alginate as immobilization material: I. Correlation between chemical and physical properties of alginate beads. Biotechnol. Bioeng. 33, 79-89.

Mathiowitz, E., Jacob, J.S., Jong, Y.S., Carino, G.P., Chickering, D.E., Chaturvedi, P., Santos, C.A., Vijayaraghavan, K., Montgomery, S., Bassett, M., Morrell, C., 1997. Biologically erodable microspheres as potential oral drug delivery systems. Nature 386, 410-414.

Morishita, M., Morishita, I., Takayama, K., Machida, Y., Nagai, T., 1992. Novel oral microspheres of insulin with protease inhibitor protecting from enzymatic degradation. Int. J. Pharm. 78, 1-7.

Moses, L.R., Dillep, K.J., Sharma, C.P., 2000. Beta cyclodextrin-insulinencapsulated chitosan/alginate matrix: oral delivery system. J. Appl. Polym. Sci. 75, 1089-1096.

Moslemy, P., Guiot, S.R., Neufeld, R.J., 2002. Production of size-controlled gellam gum microbeads encapsulating gasoline-degrading bacteria. Enz. Microbial Technol. 30, 10-18.

Onal, S., Zihnioglu, F., 2002. Encapsulation of insulin in chitosan-coated alginate beads: oral therapeutic peptide delivery. Artif. Cells Blood Substit. Immobil. Biotechnol. 30, 229-237.

Ostberg, T., Lund, E.M., Graffner, C., 1994. Calcium alginate matrices for oral multiple unit administration: IV. Release characteristics in different media. Int. J. Pharm. 112, 241-248.

Ostberg, T., Vesterhus, L., Graffner, C., 1993. Calcium alginate matrices for oral multiple unit administration: II. Effect of process and formulation factors on matrix properties. Int. J. Pharm. 97, 183-193.

Poncelet, D., 2001. Production of alginate beads by emulsification/internal gelation. Ann. N.Y. Acad. Sci. 944, 74-82.

Poncelet, D., Lencki, R., Beaulieu, C., Halle, J.P., Neufeld, R.J., Fournier, A., 1992. Production of alginate beads by emulsification/internal gelation. I. Methodology. Appl. Microbiol. Biotechnol. 38, 39-45.

Poncelet, D., Poncelet De Smet, B., Beaulieu, C., Huguet, M.L., Fournier, A., Neufeld, R.J., 1995. Production of alginate beads by emulsification/internal gelation. II. Physicochemistry. Appl. Microbiol. Biotechnol. 43, 644-650.

Quong, D., Neufeld, R.J., 1998. DNA protection from extracapsular nucleases, within chitosan- or poly-L-lysine-coated alginate beads. Biotechnol. Bioeng. 60, 124-134.

Ramdas, M., Paul, W., Dileep, K.J., Anitha, Y., Sharma, C.P., 2000. Lipoinsulin encapsulated alginate-chitosan capsules: intestinal delivery in diabetic rats. J. Microencapsul. 17, 405-411.

Shively, M.L., 1997. Multiple emulsions for the delivery of proteins. In: Sanders, L.M., Hendren, R.W. (Eds.), Protein Delivery: Physical Systems. Plenum Press, New York, pp. 199-211.

Silva, C.M., Ribeiro, A.J., Figueiredo, M., Ferreira, D., Veiga, F., 2005. Microencapsulation of $\mathrm{Hb}$ in chitosan-coated alginate microspheres prepared by emulsification/internal gelation. AAPS J., 7, article 88.

Sluzky, V., Tamada, J.A., Klibanov, A.M., Langer, R., 1991. Kinetics of insulin aggregation in aqueous solutions upon agitation in the presence of hydrophobic surfaces. Proc. Natl. Acad. Sci. 88, 9377-9381.

Tin, S.S.H., Boadi, D.K., Neufeld, R.J., 1997. DNA encapsulation by an air-agitated, liquid-liquid mixer. Biotechnol. Bioeng. 56, 464-470.

Wan, L.S., Heng, P.W., Chan, L.W., 1993. Influence of hydrophile-lipophile balance on alginate microspheres. Int. J. Pharm. 95, 77-83.

Wang, W., He, Z., 2002. Alginate-konjac glucomannan-chitosan beads as controlled release matrix. Int. J. Pharm. 244, 117-126.

Zhou, S., Deng, X., Li, X., 2001. Investigation on a novel core-coated microspheres protein delivery system. J. Control. Rel. 75, 27-36. 